www.jmscr.igmpublication.org

Impact Factor 5.84

Index Copernicus Value: 71.58

ISSN (e)-2347-176x ISSN (p) 2455-0450

crossref DOI: _https://dx.doi.org/10.18535/jmscr/v5i12.150

Journal Of Medical Science And Clinical Research

\title{
Challenges of Manpower Problems and Its Solution (With special reference to Public health sector)
}

\author{
Authors \\ Prof. (Dr.) Subhasish Chatterjee ${ }^{1}$, Prof.(Dr.) Niraj Pandit ${ }^{2}$ \\ ${ }^{1}$ Principal, Department of Management, Sumandeep Vidyapeeth, Piparia, Vadodara \\ ${ }^{2}$ Professor \& Head, Department of Community Medicine, SBKS MIRC, Sumandeep Vidyapeeth, Piparia, \\ Vadodara
}

\begin{abstract}
This review research paper has examined about the current circumstances of human resource in public health sectors. A recent trend of manpower planning says that there is necessity of improving the system of manpower planning and also to upgrade the quality of staff. India's populace dependably believes in the informations broadcast through media and many a time feeling incorrectly about the medical staff working in various regions, but in reality, the situation is completely opposite. Researchers attempted to convey that the proper matrix of human resource framework is to be developed as quickly as conceivable or else it is very difficult for the present medical staff in different categories to overhaul the situation. Researchers likewise have endeavored to convey that only existing staffs are not responsible for the contemporary situation in the public health care area.

Researchers have also examined about the procedure ought to be undertaken by the Government and the process of speculation for building up the entire framework and in further it will be praiseworthy if authority takes an initiative of enrolling workforces for successful functioning of the public health area. It is also reviewed that under what approach Government should develop skills of the present staffs by providing training in a regular interval. It is also very important to quantify the abilities of the workforce to work with the latest medical technologies.

Keywords: Public Health, Manpower/Human Recourse, Healthcare, Challenges Deficiency, Quality, Skills and Training.
\end{abstract}

\section{Introduction}

There has been a vast deficiency in employees such as nurses, paramedical staffs of all categories and particularly physicians in public health sectors at present situation. Participation of health worker and clinical expertise in remote extent is volatile in nature because of insufficient arrangement of necessities in troublesome regions, absence of strong framework for improvement of clinical and non-clinical area, absence of sincerity in professional movement and approach that are few significant issues require proceeding for strategic consideration and necessary modification. There are two unforgettable occasions scripted as black days in medical history in India in the month of August, 2016.

a) A man in Orissa carried his wife dead body on his shoulder for $10 \mathrm{~km}$ after being denied to provide ambulance. ${ }^{1}$ 
b) In Uttar Pradesh, sick son died on his father's shoulder after being denied for admission in public hospitals. $^{2}$

Despite the record of two decades consistent economic growth India still faces a great deficit in delivering basic medical facilities to the population. Columnist Mr. Karan Thakur, conveyed the real situation of health-care in our country that "India continues to face challenges on the availability of health infrastructure. Our current bed-to-patient ratio remains a cause for concern. The US has one bed for every 350 patients while the ratio for Japan is 1 for 85 . In contrast, India has one bed for every 1,050 patients. This critical lack of availability means that capacity creation needs to pick up pace to meet even the existent needs of the Indian population. India ratio is 0.7 doctors and 1.5 nurses per 1000 people are dramatically lower than the World health organization average of 2.5 Doctors and nurses per 1000. Mr. Karan Thakur also added that estimates suggest that our country needs an additional 1.54 million doctors and 2.4 million nurses today to match the global average". 3

It has already been realized by the world health that as far as infant mortality rate is concerned, India is three times higher than the China and seven times higher than $\mathrm{US}^{4}$.

Almost two-third of Indian citizens takes their treatment from private healthcare centre and the numbers of patient are increasing especially in private or multinational hospitals on regular basis. Those facilities are also not available in rural and semi-town area, for that reason people spent money and time both to reach that types of hospital. Sometimes many patients die on the way to hospital. In addition to that, there are many other difficulties face by the people while going to take treatment in the public hospitals such as long waiting, non-availability of proper medicines, lack or absence of diagnostic services, shortage of dedicated staff and scarcity of medical and paramedics' staff. Due to those reasons as well as lack of extra money for the treatment in the healthcare sector, many people of India are deprived of getting proper healthcare.

Most of the unorganized and regular wage labours face massive problems to take treatment in health care sectors because of two reasons a. they do not have enough money to take treatment in the private hospital moreover one day treatment means a relative loss of one day wage. Latest fiveyear plan for 2012-2017 foresee the role of private-public partnership to make health care to most population. ${ }^{5}$

It has been understood from the six months bulletin series of GE 'How India can overcome the doctor shortage and exorbitant costs of healthcare' that 'Much of the problem is manpower. There are 750,000 doctors in India, which amounts to only one for every 1,425 people. (Until recently, many doctors would avoid rural service, leaving an even greater void in the places that needed it most.) With an eye towards closing this gap, the Medical Council of India has discussed the idea of shortening the curriculum for students receiving Bachelor of Medicine and Bachelor of Surgery degrees, delivering them into the field a year early. It is also understood from six months bulletin series of GE and compiled by planning commission that the state of gynecological oncology illustrates this desperate need for talent. There are more than 70,000 new cases of cervical cancer, the second-most widespread type of cancer among Indian women, reported each year; India produces only one gynecological cancer specialist each year to treat that mass of diagnoses. ${ }^{6}$

\section{Review of Literature}

How to allocate public health manpower in township health centers in China scientifically and reasonably has discussed about the shortage of manpower in health sector because health care workers are the main backbone to bring the quality of health services. According to Nozibele Gcora and Liezel Cilliers a need based approach could be applied to recruit the public health manpower and a predictive model should be 
established to understand for service areas and service population. ${ }^{7}$ Skill Mix and the perfect placement of healthcare sectors manpower is a matter of challenge. Deployment of right people in a right place is great challenge of the government. Authors concluded that human resource development and proper training policy and the reorientation of medical and paramedical education and there appropriate utilization. ${ }^{8} \mathrm{~A}$ review research paper where scholars tried to find out, whether government should invest and give more support to public health? What are the role and nature of workforce, and how to strengthen them for new approach as well? Study concluded that there is requirement of Government support and rebuild the public health workforce challenges and policy issues and human resource of workforce of public health especially in developing country. ${ }^{9}$ In another review research paper scholar analyzed the social, economic, and political origins of the major challenges facing public hospitals in India despite introduction of National Rural Health Mission in 2005. Special stress is also given on few important points such as necessity of mobilization towards widest possible section society to stop the interest of dominant class and to bring to an end of the domination of the medical and healthcare profession only by the elite class. ${ }^{10}$ Revisit of past 60 years literature have been conducted, where could not find specific approach to deal with health care human resource planning. ${ }^{11}$

An article On September 01, 2016 in Hindustan times - Healthcare crisis: Short of 5 lakh doctors, India has just 1 for 1,674 people said that Millions cannot admittance India's overloaded hospitals and insufficient medical facilities, a crisis showed by the fact that India is in need of nearly 500,000 doctors. These medical-education differences reflect larger public-healthcare issues. In general, poverty is correlated with the lack of healthcare. For instance, among states with the highest proportion of undernourished children, Jharkhand and Chhattisgarh have the worst infrastructure for institutional deliveries. A report of 2015 says that there is a shortage of medical and paramedical staffs in the country. Above all there is a shortage of $83 \%$ specialist medical professional in public and community health centre. ${ }^{12}$ India Spend reported in February 2016, centers of Publichealth in entire India, rural areas-25,308 in 29 states and seven union territories- there is a deficiency of 3,000 doctors, the insufficiency rising 200\% (or tripling) for last 10 years, India Spend reported in February 2016. ${ }^{13}$

\section{Objective}

To discuss about challenges of manpower shortage and its necessary solution in public health area.

\section{Research Methodology}

As we probably aware, that the primary information is gathered in view of the interest of the investigator with the individuals who have been selected as sample but on the contrary, secondary informations are gathered on the basis of the regular search from the various sources. . Many sources are connected with the purpose of probing correct answer of the questions (objective) propounded by the researcher.

Therefore, following analysis is completely drawn upon the availability of various research papers available in different journals, books, government documents and from various web sources.

\section{Discussions}

Accessibility of health care professionals in rural areas on a regular basis is challenging duty of human resource department, in order to ensure the same few process are outlined for suggestions.

\section{a Quality of staffs}

Suggestion: Considering the overwhelming populaces and the rising numbers of different types of ailments, it is high time of Government to train many of the health professionals to upgrade the quality of staff health especially in rural India. Government has special structure of National 
Institute of Health and Family Welfare and State Institute of Health and Family Welfare. Their key role is in training. They have regular calendar of training program for new joining health cadre like medical officer, laboratory technicians, pharmacist, nurses, male workers, female workers and all such cadre. In addition each district has district training team and their team is regularly providing on-job training to in service staff. This is very good concept but due to some reasons it is not presently functional up to mark.

\section{b. Lack of facilities and its possible solutions}

I. Require to reorganize of different employees of medical fraternity, especially doctors of different specialist are not a simple assignment until and unless the government provides them various monetary as well as nonmonetary facilities such as retirement age, which is a vital issue to be taken into genuine thought by the government, especially in the public sectors because of inadequacy of doctors', it might decrease if their retirement age increasing from 62 to 65 years; it may also extend up to 70 years by appointing to contract with regular intervals interim.

II. In addition to that compassionate ground posting of spouse will make the employee comfortable to stay in the same place for quite a while. Spouse posting in the same place will not only give an added advantage to the employee but it will likewise provide an advantage to the government for getting minimum two medical/paramedics staff in one place.

III. Suitable facilities for children education should be considered as one of the prime criteria. On the other hand, their children ought to get admission in their preferential school or if their children take admission in a residential school in different cities than they should get special preference.

IV. Suitable accommodations with few ancillary facilities are also one of important criteria to retain the employee in the rural area.
V. Government should grant fund to smooth the progress of forming wives welfare associations. This type of association will pursue housewives engaging in different activities, which shall feel them free from monotonous life in remote villages.

\section{c. Private Practice inclination of Government} Physicians and its possible solutions.

Private practice is additionally one of significant issue to discuss, as far as author's view is concerned: Government should not encourage appointed doctors for private practice but rather there must be a lucrative non practicing allowance, which will keep them away from that type of mesmerizing dream. Moreover, introducing incentives is also one of the important issues to consider for doctors as well as other paramedics also.

d. Administrative Burden physicians and rest of the staffs and irrational Manpower planning and its solutions

I. Heavy administrative burden of doctors is another critical issue, which kills their clinical skills. It implies that there are many doctors lost their clinical skills by being dumped of lots of administrative work by government in public health sectors. So government should construct right manpower planning by analyzing their work specialization and they should be posted according to their job description.

II. So, decentralization of different skilled staffs of health sectors as a permanent posting towards rural area ought to be the most significant step to minimize the deficiency in manpower. Notwithstanding that there is a requirement to apply the system of contractual appointment process of all categories. Additionally, honorary consultant framework should be made, so that a variety of top private practitioners and retired professors may be attached to various colleges as visiting and adjunct faculty. They may likewise be presented as advisors in 
different areas of public health and community medicines.

III. Undoubtedly, there is a need of staffs on contract category at present situation but it would be better if Government takes a step to fill up all vacancies only by permanent staffs. It has been observed that contractual staffs are always taking their work very lightly because, there is a practice of stepdaughter's treatment everywhere to the contractual workers in there working place, although the permanent staffs, because of their better job security as compared to workers on contract, always understands their value and accountability.

\section{e. Inadequate Human Resource Development and its solutions}

i. MBA (Health care) and B.Sc (Health Sciences) courses are very rewarding courses of the health workers. Government should take a special initiative to pursue the non-clinical health care worker to complete this course, which shall equip them with knowledges about different health issues. They will have many important duties in health service management by holding various designations such as health researchers, health managers and a health promotion executive. Those workers are commonly being measured as front line managers, who have a direct link with the grassroots people. Top Management of district health centers will take decision based on their reports. Moreover, they are also critically dealing with many important health issues such as locale health, antitobacco \& anti smoking campaigns, drug and alcohol consumptions, chronic disease, women and child health and of course they also try to make the people understand about different communicable disease. So, government should either start institute of these programs in all districts or make a tie- up with different existing institutions conducting these courses.

ii. It is essential to take an endeavor to establish new medical colleges especially in the rural region to serve the rural society as a center of excellence by taking into account of social obligation and community development, medical education, research and health care. An effort should make to form a 'Public-private partnership' structure, which may reduce the deficiency in all areas of the public health in future days to come.

iii. It is crystal clear that community medicine deals with many important areas, in broader sense Epidemiology, Biostatistics, Demography, Nutrition, Preventive medicine, Health administration \& planning and Behavioral science but, in present situation there are many loopholes have been detected between planning and implementation. So it requires strengthening the implantation process as fast as possible. In addition to that proper application of sociological concept such as gender equity and behavior is to be taken into the considered with immediate effect. For two important subjects such as medical sociology (the study of cultural factors and social relations in relation to illness) and sociology for health ------ a need of many health workers possessing a degree of sociology. Apart from medical sociology they will also make vigilance and progress few other areas in the community such as social pathology, social stress, standard of living -communication and social pathology. In that regards, government must take an initiative to develop few institutions especially in the rural area and local lads should be given priority to admit this types of skilled course.

It will not only upgrade the situation of society and community medicines but also 
reduce the rate of unemployment in the rural sectors.

iv. Implementation of CME Programs, computer networking of medical colleges, promotion of IT-based e-health, teleconsultancy, tele-radiology and telepathology are necessary. Many villages in India are unreachable and people of those villages are suffering from the cause not to have proper medical treatment because of deficiency of medical, paramedical staffs, medicines and testing equipment. So, teleconsultancy cum telemedicine is one of the prospective medium to reach them.

v. To strengthen the IT -based e-health procedure inclusive of tele-consultancy, government should take it as one of the significant agenda that will help the people who are staying in remote villages. A special cell must be formed into all medical colleges and each cell should deal with the villages of its closest area. Each medical college will be accountable to strengthening the tele-consultancy process of those villages. In addition to that there should be a mandatory policy that each and every multi specialty hospitals or nursing home or hospitals in any shape will have to adopt few villages as a part of their social responsibility. They have to have one cell to deal with their adopted villages through tele-consultancy or any other process.

vi. Public health and community medicines are no longer the space of a couple of medical experts and ought to be the center to nurses and midwives. Nurses and midwives are very significant workers who are directly able to reach to the women fraternity in the village. They are the only grassroots workers can understand the reality of public health; they are especially engaged with women and child health, which they can express the reality of their parental organization where they are working. That will of course exhibit that nurses and midwives are always able to upgrade the lifestyle of the rural people and ensure the best services in public health. But unfortunately, acute deficiency in nursing staffs causing very fewer services in public health and community medicines. In order to set up the growing demand for nursing staffs, there is an instant need to start GNM, B.Sc. and MSc. Nursing Schools/Colleges in each district. BSc and MSc qualified nurses can fill up the post of tutor in different nursing schools, where Government can start various certificate courses of different skills. In continuation to that, each and every school should open one cell for e-training and teachers deputed in those schools should expert in tele-training and should able to update different nurses working in different remote villages. There is a requirement of opening good number of nursing schools and also need to increase seats of admission in different schools for General Nursing Midwives and Auxiliary Nursing Midwives courses because they are the most significant workers working in the grassroots level. Later on government should give them the opportunity for higher studies like Post basic BSc, MSc and $\mathrm{PhD}$ and therefore government should extend few special facilities like study leave with full salary and study loan facilities without interest.

vii. Capacity development program for managers time and again is very important agenda to be taken as a supreme function of human recourse department. Public health program for managers brings together and deal with healthcare services and other services too. They are usually designated either as health information managers or clinical managers. The job of the Clinical managers is to create and keep up different policies and through the doctors as per policies and process of work they draw to get good result. Their duties are not 
restricted to direct the doctor but they also keep close observation of the performance of rest of the medical as well as paramedics. Clinical managers are also engaged in preparing financial planning with the people working in that particular domain. Being a clinical manager his duty is not limited to clinical people but also it has to be extended up to administration and coordination with all types of non-clinical staffs. Health information managers are accountable for preserving record of patient systematically. Security of the record and up-to-date of all records on daily basis is an important duty of health information managers. Understanding the latest public health management process of different developed countries, the capacity development of the following areas need to give on priority basis such as formulation of policies and its appropriate implantation, policy analysis in research sectors, well verse on strategic management and leadership abilities, monitoring community, skills development in financial management for proper budgeting and accounting, communications skills, research formulation data analysis and report writing, micro-planning and developing motivation and abilities to transfer skills to other workers.

viii. Apart from that there is needed to introduce a course of public health management in different colleges. In addition to that is would be better to give a scope of the in service staff to pursue 'Diploma in Public Health Management 'on part-time mode.

ix. A successful human resource information system is also vital for foretelling the prospect manpower necessities. The only barrier that stops in reducing the gap between demand and supply to human resource is non-other than lacking of proper human resource information technique. There are many functions of human resource information system like collection
\& storing of data, appointment processing, promotion, training/ management development, transfer/relocate and detail of compensation and performance appraisal. Expanding Human Resource Information system (HRIS) functions and data whatever has been collected should be used for decision making. Data entry and arranging it serially is not enough effort of human resource information system, there must be a compulsion to analysis data onto decision making in different areas such as 'personnel database recruitment, performance evaluation, training and development, performance evaluation, compensation and benefit, people administration, pay roll, leave and absence, promotion, reward and value addition'.

\section{f. How to reorganize the Human resource system.}

There should be a data handling and decision making department in Ministry of health. The Director (Human Resource) of that department must have the responsibility to take the decision based on the data, updates in a regular mode from all Districts, Block and even Primary Health Centre.

Incorporation of public health data onto HRIS should be given a prime importance by the Human Resource Department. The department must divide the entire data completely based on skills of health workers and the functions HRIS department should not be limited just entering numbers only, in such case there is a requirement validating, analyzing and updating of data.

Training and orientation of all medical and paramedical personnel on the public health matters will also go a long way in the management of diseases and epidemics. In these cases departments of 'Human Resource Information system' can give the right informations time and again to the 'Human Resource Training Department' to update the skills. 
The total Management Information System should be divided into three department

HRIS should operate in each \& every level such as State level, District level, Block level and PHC level and that shall be controlled by only Human Resource Department along with software and maintenance experts.

Human resource department should be powered with autonomous capacity and shall be reporting to the secretariat of health department concerning to vacancies and rest others areas that come under domain of Human Resource Management.

\section{g. Strengthening the private- government bond}

Due to rapid growth of medical technology and high rise of medicines price and other consultancy charges, it is practically difficult for any single organization to provide proper service to the patients in the present global situation. In that case, there is requirement of institutional, government- private or the partnership between global hospitals. In addition to that there is an emergent need of partnership between development of new and innovative approaches to tackle public health issues.

Undoubtedly, health service in public health system is very disgraceful as compare to public health service of any other countries in the world. The public sector is not efficient enough to provide good service to poor patient. In that situation, maximum poor patients knock the door of private sectors hospital where they get the better treatment than public health sectors. But unfortunately they pay their medical expenses beyond of their capacities. In maximum cases, unquestionably most of the private hospitals and nursing homes are unregulated India. There are many evidences found concerning to the exorbitant hospital and nursing home charges, which forces the poor people to borrow money from different moneylender with high interest. Private sectors attitude to overcharging to the patients and inefficiency of smooth the progress of proper treatment of hospitals under government domain, there is an immediate requirement of public health sectors to set off for collaboration with the private sectors. This thought process converted into the practice in many states in India, despite that there are many sectors where 'unregulated process' still prevails. So there is an immediate requirement to rectify the matters and to strengthen the process of treatment and service as well.

x. Medical college - reshaping ex students There is a requirement of a cell in all medical colleges to retrain their ex-students, who are engaged as permanent or contractual employee under the domain of public health and community medicines. Retraining of ex students through online computer training should also be taken under active consideration in all medical colleges in India. In that pattern of services the alumni association should have active participation. On the other hand, public health department in all level should encourage retraining of medical staffs and should make a practice to provide necessary leave for that purpose.

xi. Promulgating of mandatory policy of each and every multinational/private/public hospitals/ nursing homes to adopt one district for on-job training as well as of-job training. For that particular reason, there must be one cell in each and every hospitals/ nursing homes. Each cell has to recruit few competent persons, who will be responsible to conduct regular learning process. Each cell can take either block or primary health centre as per competence.

We must track various multinational hospitals/ nursing homes to make them realize concerning their social responsibility as institutes.CPD i.e. 'continues professional development' of medical and paramedics as when required is one of the most important issues needs to be recognized as social responsibility of each and every private and government hospitals as well. The best practice would be the online training and updating the different employee engaged in public health. Educate or upgrade the health care sector through 
Electronic learning (e-learning) in the health care sector is none other than the freedom of Continued Professional Development with the help of Smartphone, videoconference, and other media. E-learning is accepted as one of the most important encouraging practice for learning on ground level and as a consequence, e-learning series set aside the active workers working in health care sectors to admittance in learning prospects.

In addition to that, sometimes external resources are required not only for disastrous management but also to diminish the gap between demand and supply to human resource in public health area. In that case different multinational/private/public hospitals/ nursing homes can take the responsibility for the area they have adopted. They must make a bond/agreement with their medical staffs in all sectors working in the public health area as and when required. Resources from international sectors especially from western country will also be a great foundation of human resource for learning and upgrading the public health sectors.

\section{Conclusion}

After examining the situation of human resource in the public health area in the Indian perspective, it is understood that the people of rural area are regularly experiencing many difficulties in availing medical care with various most up-todate facilities of public health and community medicines because of less number of healthcare professionals. The maximum numbers of physicians posted in rural regions are general physician. Deficiency in specialized physicians in different domain is very common setbacks in public health and community medicines. Few of the important matters are required to be given priority by the Government to develop the public health care system such as to enhance the financial budget, to support for the development of ultra modern medical technology, to improve the management information system and to establish proper training and development cell i.e. few hubs knowledge capital in different rural place. The negligence of medical care of rural region is not only the India's problem; this problem exists in many countries in the globe. Just for the sake of skipping their responsibility, Government authorities are always bypassing their accountability to a healthcare professional such as physicians, nurses and paramedical staffs, but the fact is that, maximum numbers of healthcare professionals in India are highly dedicated towards their work. Government should understand the ratio of the rural population and the number of health care professionals supplied to that place. It has already been calculated by many researchers with the help of statistical formula that the ratio of healthcare employee compares to rural population is very stumpy. In that regards, the funniest thing is that in India, the number of physicians available is low and on the contrary, the number of physicians in German is surplus. After previously mentioned discussions it is clear that there is a necessity of gigantic advancement of the system and procedure of Human asset development and management. To redesign all that there is additionally needing of rehearsing which will influence the general population to comprehend the realness of the strategies. It assumes a critical part in providing the skilled and short supply individuals in various domains in the healthcare system. So we should find a way to understand the skilled and short supply and ought to adopt a procedure which can make an appropriate flow human asset as when required. Another critical issue is to be considered by the government about the serious concern of providing low quality or half trained individuals to the health care framework. In that event, the government must take a grave intervention to build up the quality of the workers.

\section{Reference}

1. Hindustan Times, August 25, 2016.

2. Hindustan Times, August 30, 2016. 
3. Mr. Karan Thakur,'Mind the Gap: Health workforce shortage', Pioneer, $7^{\text {th }}$ August, 2017.

4. https://qz.com/266154/why-indian-lifespans-continue-to-be-shorter-than-thoseof-other-developing-and-developednations/

5. shodhganga.inflibnet.ac.in

6. https://qz.com/269392/how-india-canovercome-the-doctor-shortage-andexorbitant-costs-of-healthcare/

7. Yue $\mathrm{Hu}^{\otimes}$ and Jiaying Chen, How to allocate public health manpower in township health centers in China scientifically and reasonably, J Biomed Res. 2014 Mar; 28(2): 78-80.

8. Deoki Nandan, K.S. Nair and U.Datta, Human resources for public health in India -Issues and Challenges, Health and Population - Perspectives and Issues 30 (4)230-242, 2007.

9. Beaglehole and Dal Poz, in their research paper Public health workforce: challenges and policy issues, Human Resources for Health, 2003.

10. Vikas Bajpai, The Challenges Confronting Public Hospitals in India, Their Origins, and Possible Solutions, Advances in Public Health Volume 2014 (2014),

11. Amorim Lopes, Álvaro Santos Almeida and Bernardo Almada, Handling healthcare workforce with care: where do we stand, Human Resource for Health(2015)

12. Hindustan times - Healthcare crisis on September 01, 2016.

13. India Spend report, February 2016

\section{Bibliography}

1. An Overview of Public Private Partnerships in Health: Marc Mitchell, M.D., M.S. Harvard School of Public Health.

2. BURTON, L. E.; SMITH, H. H., Public health and community medicine for the allied medical professions.

1970 pp.xiv+561 pp.

3. From past to present; the changing focus of public health: by Maria Joyce eprints.lincoln.ac.uk/1839/2/Public_health _paper.doc.

4. Fan M. Investigation on the current situation of health human resources of rural township hospitals in Liaoning. Chin J Public Health (in Chinese) 2004;20:376

5. Human Resources Information Systems (HRIS): A Review across States of India: Dr. Manju Shukla, Shalini Verma, Madhuri Narayanan, and David Potenziani, IntraHealth International, Jue, 2014

6. Handling healthcare workforce planning with care: where do we stand? Mário Amorim Lopes,Álvaro Santos Alme ida and Bernardo Almada-Lobo, Human Resources for Health2015.

7. K. Rao, A. Bhatnagar, and P. Berman, "India's health workforce: size, composition and distribution," in World Bank/Public Health Foundation of India, J. La Forgia and K. Rao, Eds., India Health Beat, New Delhi, India, 2009.

8. Nozibele Gcora, Liezel Cilliers, Critical success factors for eLearning adoption in the public health care sector in South Africa:

http://ieeexplore.ieee.org/document/75306 00/?reload=true: ISBN: 978-1-9058-24557: 08 August 2016.

9. Nie CL, Li JY, Jia CP, Sun Y. Evaluation on allocation of health manpower resources of China in 2000. Chin Prim Health Care (in Chinese) 2004;18:14-5.

10. Telemedicine: A New Horizon in Public Health in India:Aparajita Dasgupta and Soumya Deb: Indian J Community Med. 2008 Jan; 33(1): 3-8.

11. Zh ang J, Feng ZC, Zhang L, Zhang X, Xiong JY. Discussion on the allocation scheme of rural health human resources of 
township hospitals. Med Soc (in Chinese) 2006; 19:52-3.

12. Zheng WJ, Wu YY, Sun JW, Zhang S, Chen K. Research on public health manpower resources. Health Econ Res (in Chinese) 2008:46-7.

13. http://planningcommission.nic.in/news/ddi gest/oct14/Daily\%20Digest\%2030th\%200 ctober\%202014.pdf.

14. http://www.nihfw.org/WAboutUS.aspx

15. http://sihfwrajasthan.com/ 